\title{
Analysis of Nanofluids as Cutting Fluid in Grinding EN-31 Steel
}

\author{
V. Vasu ${ }^{1, *}, \quad$ K. Manoj Kumar ${ }^{2, *}$
}

(Received 13 August 2011; accepted 22 September 2011; published online 3 November 2011.)

\begin{abstract}
Grinding requires high specific energy which develops high temperatures at wheel work piece interface. High temperatures impair work piece quality by inducing tensile residual stress, burn, and micro cracks. Control of grinding temperature is achieved by providing effective cooling and lubrication. Conventional flood cooling is often ineffective due to enormous heat generation and improper heat dissipation. This paper deals with an investigation on using TRIM E709 emulsifier with $\mathrm{Al}_{2} \mathrm{O}_{3}$ nanoparticles to reduce the heat generated at grinding zone. An experimental setup has been developed for this and detailed comparison has been done with dry, TRIM E709 emulsifier and TRIM E709 emulsifier with $\mathrm{Al}_{2} \mathrm{O}_{3}$ nanoparticles in grinding EN-31 steel in terms of temperature distribution and surface finish. Results shows that surface roughness and heat penetration were decreased with addition of $\mathrm{Al}_{2} \mathrm{O}_{3}$ nanoparticles.
\end{abstract}

Keywords: Grinding; $\mathrm{Al}_{2} \mathrm{O}_{3}$ nanoparticle; Temperature distribution; Surface roughness; EN-31 steel

Citation: V. Vasu and K. Manoj Kumar, "Analysis of Nanofluids as Cutting Fluid in Grinding EN-31 Steel", Nano-Micro Lett. 3 (4), 209-214 (2011). http://dx.doi.org/10.3786/nml.v3i4.p209-214

\section{Introduction}

Grinding is an abrasive material removal process, which is widely used in manufacturing compoents requiring fine tolerances and smooth finishes. Grinding process generates extreme heat and high cutting forces at workpiece wheel interface [1]. Cooling and lubrication are necessary to protect the workpiece and wheel from workpiece burn, phase transformations, undesirable residual tensile stresses, cracks, reduced fatigue strength, and thermal distortion and inaccuracies [1-2]. When the cutting fluid is applied to the grinding zone, it will initially undergo nucleate boiling, which enhances the rate of heat transfer between the workpiece and the fluid. As the temperature increases further, a vapour film is developed between the workpiece and the fluid, which acts as an insulator and prevents heat transfer to the fluid. As a result, the workpiece temperature quickly rises and burns the surface of the material [3].

An alternative to flood cooling is Minimum Quan- tity Lubrication (MQL) or use of Solid Lubricants. MQL gives similar results as that of flood cooling if the coolant in MQL does not evaporate due to the grinding heat [4]. Solid lubricants demonstrates satisfactory properties in grinding due to sustain of high temperature, nontoxic, easy to apply and cost effective $[5,6]$. Instead of good results of solid lubrication, there is still a need for flushing action and tool cleaning make less attractive than conventional liquid lubrication methods. Due to emerging of nanotechnology, high thermal conducting fluids called 'Nanofluids' has emerged. Nanofluids are engineered colloidal suspension of nanoparticles $(10 \sim 100 \mathrm{~nm})$ in base fluids [7]. The applicability of the fluids as coolants is mainly due to the enhanced thermo-physical properties of fluids due to the nanoparticles inclusion [8].

In this paper the effect on surface roughness and heat dissipation by suspending $\mathrm{Al}_{2} \mathrm{O}_{3}$ nanoparticles in eco-friendly emulsifier TRIM E709 in machining EN-31 steel at different speed-feed-depth of cut combinations are observed.

\footnotetext{
${ }^{1}$ Asst. Professor, Department of Mechanical Engineering, National Institute of Technology Warangal 506004, India

${ }^{2}$ Research Scholar, Department of Mechanical Engineering, National Institute of Technology Warangal 506004, India

*Corresponding author. E-mail: vvvasu@gmail.com, manojkumar.konduru@gmail.com
} 


\section{Synthesis of Nanofluid}

Alumina nanoparticles are prepared by Liquid Phase Synthesis [9] of Ammonium Aluminum Carbonate Hydroxide (AACH) followed by thermal de- composition (calcination). Then, nanofluid is prepared by mixing $\mathrm{Al}_{2} \mathrm{O}_{3}$ nanoparticles into an emulsifier TRIM E709 by stirring for about 8 hours continuously using magnetic stirrer as shown in Fig. 1(c).

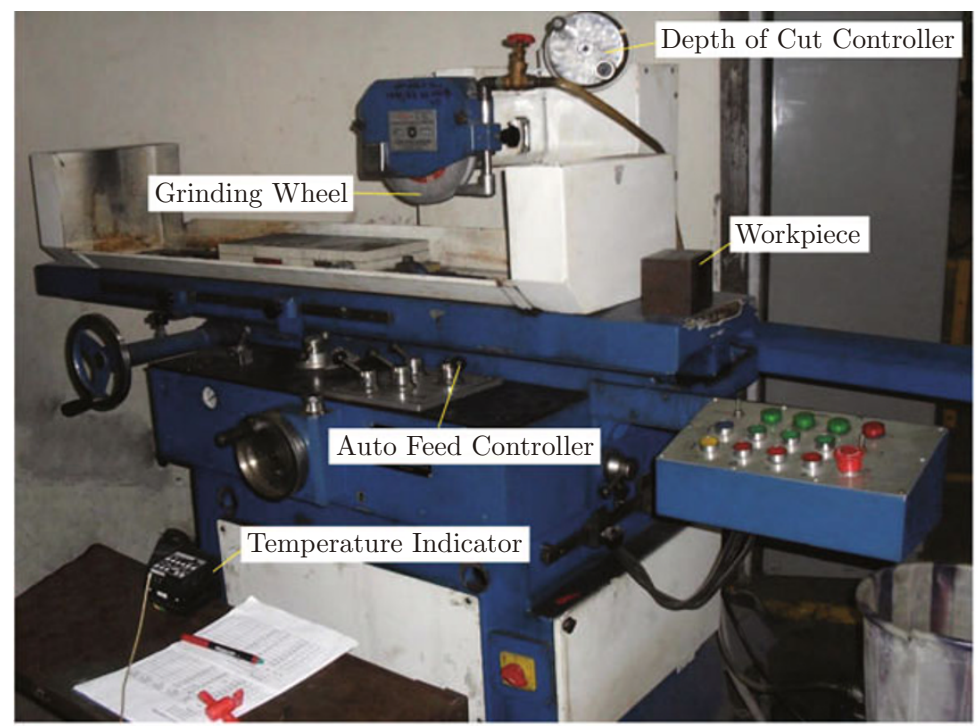

(a) Photographic view of the experimental setup
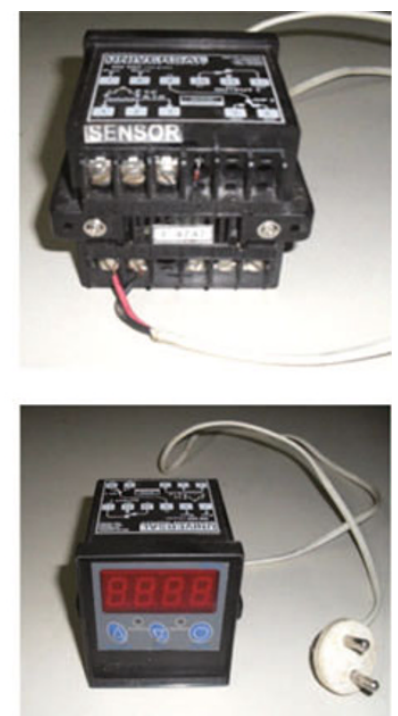

(b) Temperature indicator

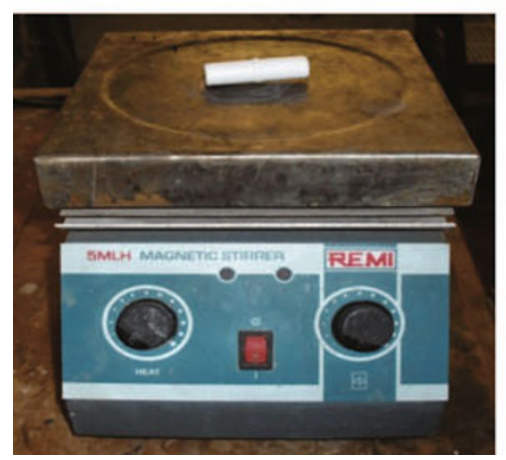

(c) Magnetic stirrer

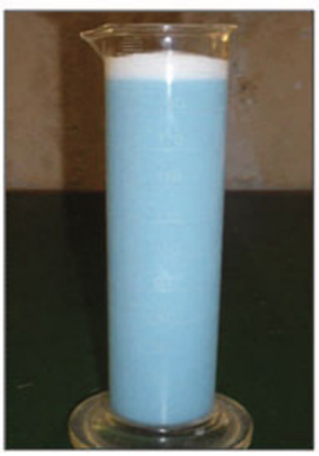

(d) TRIM E709 Emulsifier

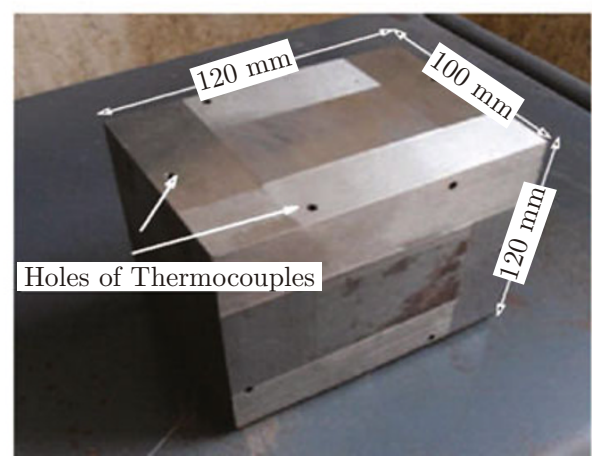

(e) EN-31 Steel work piece

Fig. 1 Experimental Setup and its apparatus.

\section{Experimental procedure}

Figure 1 shows the experimental setup for present studies, an EN-31 steel block of initial $100^{*} 120^{*}$ $120 \mathrm{~mm}^{3}$ is machined using LAMBA grinding machine at different speed-feed-depth of cut combinations (see Table 1\&2) under dry condition, wet (emulsifier TRIM E709) condition and emulsifier TRIM E709 with $1 \%$ $\mathrm{Al}_{2} \mathrm{O}_{3}$ nanofluid condition to study the role of $\mathrm{Al}_{2} \mathrm{O}_{3}$ nanoparticles on the machinability characteristics of the work material mainly in respect of surface roughness and heat dissipation. The total number of experiments according to full factorial design was 9 , by taking feed and depth of cut at three levels for three different environments. The design of experiments for the full factorial design is shown in Table 3 . Temperature measure- ment is done by using J-Type thermocouples which are incorporated at a distance of $5 \mathrm{~mm}$ from all the edges of the workpiece as shown in the Fig. 1(e).

Table 4 shows experimental results for surface roughness, wheel work piece interface temperature under different environment conditions. From results as shown in Table 4, it is found that emulsifier $+\mathrm{Al}_{2} \mathrm{O}_{3}$ nanoparticles shows reduction in surface roughness and interface temperature than dry and plain emulsifier conditions.

Table 1 Control Factors and their levels.

\begin{tabular}{cccc} 
Control Factors & \multicolumn{3}{c}{ Levels of factors } \\
\cline { 2 - 4 } & 1 & 2 & 3 \\
Feed (mm/sec) & 100 & 150 & 200 \\
Depth of cut (microns) & 25 & 50 & 75
\end{tabular}


Table 2 Grinding Machine specifications.

Grinding mode
Grinding machine
Max. Stroke length
Max. Cross feed
Work area
Grinding wheel
Wheel size
Wheel speed
Environments
Workpiece material
Dressing tool

Surface Grinding

LAMBA Press Hydraulic Surface Grinder $750 \mathrm{~mm}$

$$
235 \mathrm{~mm}
$$

$450 \mathrm{~mm} \times 200 \mathrm{~mm}$

$\mathrm{Al}_{2} \mathrm{O}_{3}(\mathrm{AA} 46 \mathrm{~K} 5 \mathrm{~V} 8)$

$250 \mathrm{~mm} \times 25 \mathrm{~mm} \times 76.2 \mathrm{~mm}$ $1400 \mathrm{RPM}$

Dry, Wet, $1 \% \mathrm{Al}_{2} \mathrm{O}_{3}$

EN-31 Steel

Single Point Diamond Tool
Table 3 Full Factorial Array of experiments.

$\begin{array}{ccc}\text { Run order } & \text { Feed, } \mathrm{V}_{\text {wp }}(\mathrm{mm} / \mathrm{sec}) & \text { Depth of cut, d }(\mu \mathrm{m}) \\ 1 & 100 & 25 \\ 2 & 100 & 50 \\ 3 & 100 & 75 \\ 4 & 150 & 25 \\ 5 & 150 & 50 \\ 6 & 150 & 75 \\ 7 & 200 & 25 \\ 8 & 200 & 50 \\ 9 & 200 & 75\end{array}$

Table 4 Experimental Results.

\section{Run order}

\begin{abstract}
Temperature, $\mathrm{T}\left({ }^{\circ} \mathrm{C}\right)$
\end{abstract}

$\begin{array}{ccc}\text { Dry cutting } & \text { Wet cutting } & \begin{array}{r}\text { Wet cutting with } \\ 1 \% \mathrm{Al}_{2} \mathrm{O}_{3}\end{array} \\ 145 & 118 & 92 \\ 149 & 121 & 99 \\ 154 & 126 & 103 \\ 146 & 119 & 98 \\ 157 & 128 & 109 \\ 163 & 134 & 114 \\ 160 & 129 & 108 \\ 166 & 136 & 114 \\ 170 & 143 & 120\end{array}$

\begin{tabular}{ccc}
\multicolumn{3}{c}{ Roughness, $\mathrm{Ra}(\mu \mathrm{m})$} \\
Dry cutting & Wet cutting & $\begin{array}{c}\text { Wet cutting with } \\
1 \% \mathrm{Al}_{2} \mathrm{O}_{3}\end{array}$ \\
& & 0.57 \\
1.03 & 0.77 & 0.6 \\
1.06 & 0.79 & 0.63 \\
1.11 & 0.79 & 0.57 \\
1.02 & 0.76 & 0.62 \\
1.04 & 0.82 & 0.68 \\
1.14 & 0.89 & 0.69 \\
1.12 & 0.93 & 0.78 \\
1.16 & 0.96 & 0.81 \\
1.17 & 0.98 &
\end{tabular}

\section{Finite Element Model}

A finite model is proposed by considering the grinding wheel as a rectangular heat source of length equal to geometrical contact length $\mathrm{L}_{\mathrm{c}}$, between the grinding wheel and the workpiece as shown in Fig. 2. The heat source moves along the surface of the workpiece at a speed equal to the work speed along the grinding zone, $\mathrm{L}_{\mathrm{c}}$ is calculated using Eq. (1).

$$
L_{c}=\sqrt{d_{w} \times d}
$$

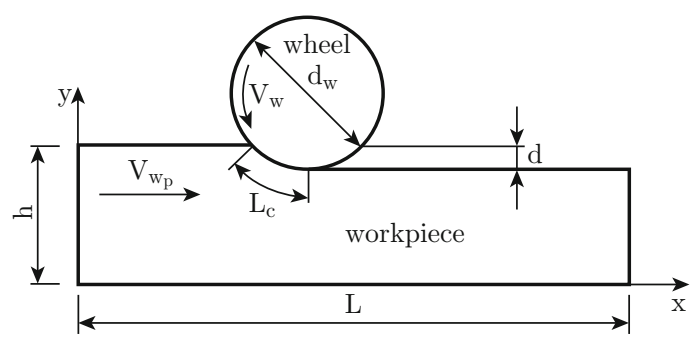

Fig. 2 Nomenclature of grinding process.

The heat generated in the grinding zone during wet grinding is transferred into the chip, grinding fluid, wheel, and workpiece. Length of heat input is half of the length of contact [2] given as

$$
L_{h}=\frac{L_{c}}{2}
$$

Cooling is simulated by means of convective boundary conditions. Top surface with a convective heat transfer coefficient of coolant, sides and bottom surfaces were given convective heat coefficient of air $(h=11.43$ $\left.\mathrm{w} / \mathrm{m}^{2} \mathrm{k}\right)$.

PLANE55 (2D, Quadrilateral, 4-node) element is used to mesh the workpiece, having more density at machining area and decrease as move away from the cutting zone, for better distribution of temperature and also to reduce computational time. The mesh details of workpiece for different depth of cuts $25 \mu \mathrm{m}, 50 \mu \mathrm{m}$ and $75 \mu \mathrm{m}$ as shown in Table 5.

Table 5 Meshing of elements at different depth of cut.

S.No Depth of Cut in $\mu \mathrm{m} \quad$ No. of Nodes No. of Elements

$\begin{array}{llll}1 . & 25 & 2236 & 2125 \\ 2 . & 50 & 1196 & 1125 \\ 3 . & 75 & 1326 & 1250\end{array}$


The top surface is applied with a heat transfer coefficient calculated from Reynolds, Prandtl and Nusselt numbers and the remaining three surfaces were applied with air convection. The convective heat transfer coefficient for nanofluids was calculated by using equation (3) and thermo-physical properties of nanoparticle and base fluid as given in Table 6 . The thermophysical properties of Nanofluids [10] is calculated by using the equations (5-7).

The heat transfer coefficient of nanofluid for flow over a flat plat can be calculated as

Turbulent Flow:

$$
N u_{n f}=0.453 R e_{n f}^{0.5} \operatorname{Pr}_{n f}^{0.333}
$$

Laminar Flow:

$$
N u_{n f}=0.332 R e_{n f}^{0.5} \operatorname{Pr}_{n f}^{0.333}
$$

where, $R e_{n f}$ and $P r_{n f}$ defined as

$$
R e_{n f}=\frac{\rho_{n f}^{V L}}{\mu_{n f}}, \quad \operatorname{Pr}_{n f}=\frac{c_{n f} \mu_{n f}}{k_{n f}}
$$

The density, specific heat and viscosity of nanofluids are

$$
\begin{aligned}
& \rho_{n f}=\phi \rho k_{p}+(1-\phi) \rho_{f} \\
& C_{p, n f}=\frac{\phi\left(\rho c_{p}\right)_{p}+(1-\phi)\left(\rho c_{p}\right)_{f}}{\rho_{n f}} \\
& \mu_{n f}=\mu_{f}\left(1+39.11 \phi^{2}+533.9 \phi^{2}\right)
\end{aligned}
$$

where, $\phi$ is particle volume fraction and subscripts $n f, p$ and $f$ correspond to nanofluid, particle, and base fluid, respectively.

\section{Results and Discussions}

Figure 3 shows the variation of temperature and Fig. 4 shows surface roughness for different coolant environments under different feed and depth of cut combinations. The variations of surface roughness and interface temperature variation for different control factors and cutting environments are discussed below.

Table 6 Properties of Cutting Fluids.

$\begin{array}{cccc}\text { Property } & \mathrm{Al}_{2} \mathrm{O}_{3} & \text { Emulsified cutting fluid } & 1 \% \mathrm{Al}_{2} \mathrm{O}_{3} \text { nano cutting fluid } \\ \text { Density }\left(\mathrm{kg} / \mathrm{m}^{3}\right) & 3970 & 931 & 961.39 \\ \text { Viscosity }\left(\mathrm{NS} / \mathrm{m}^{2}\right) & - & 0.274 & 0.3958 \\ \text { Specific Heat }(\mathrm{J} / \mathrm{kg}-\mathrm{k}) & 770 & 4198 & 4056.4 \\ \text { Conductivity }(\mathrm{W} / \mathrm{m}-\mathrm{k}) & 40 & 0.883 & 0.908\end{array}$
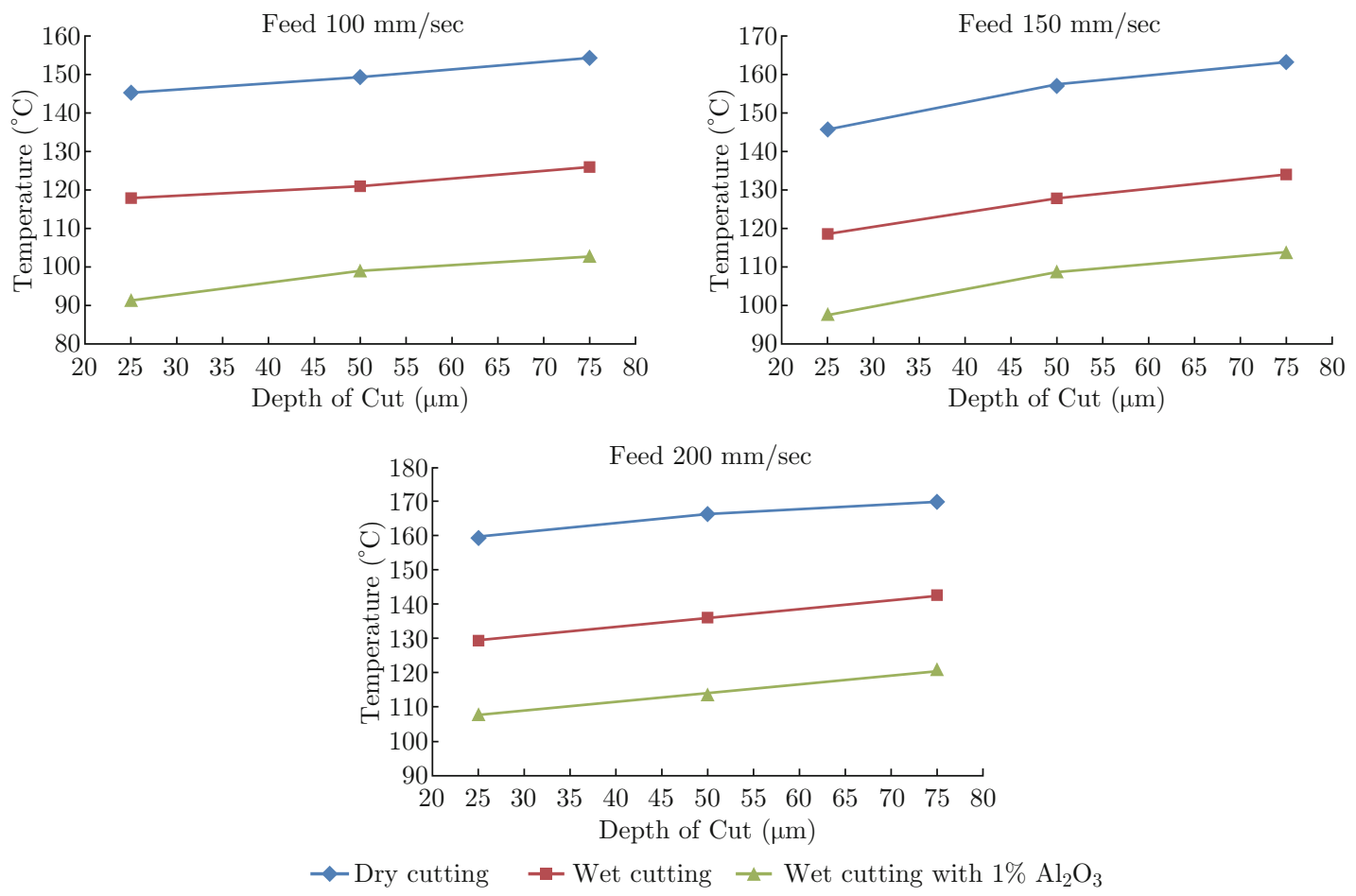

Fig. 3 Variation of Temperature for different cutting environments. 
Nano-Micro Lett. 3 (4), 209-214 (2011)/ http://dx.doi.org/10.3786/nml.v3i4.p209-214
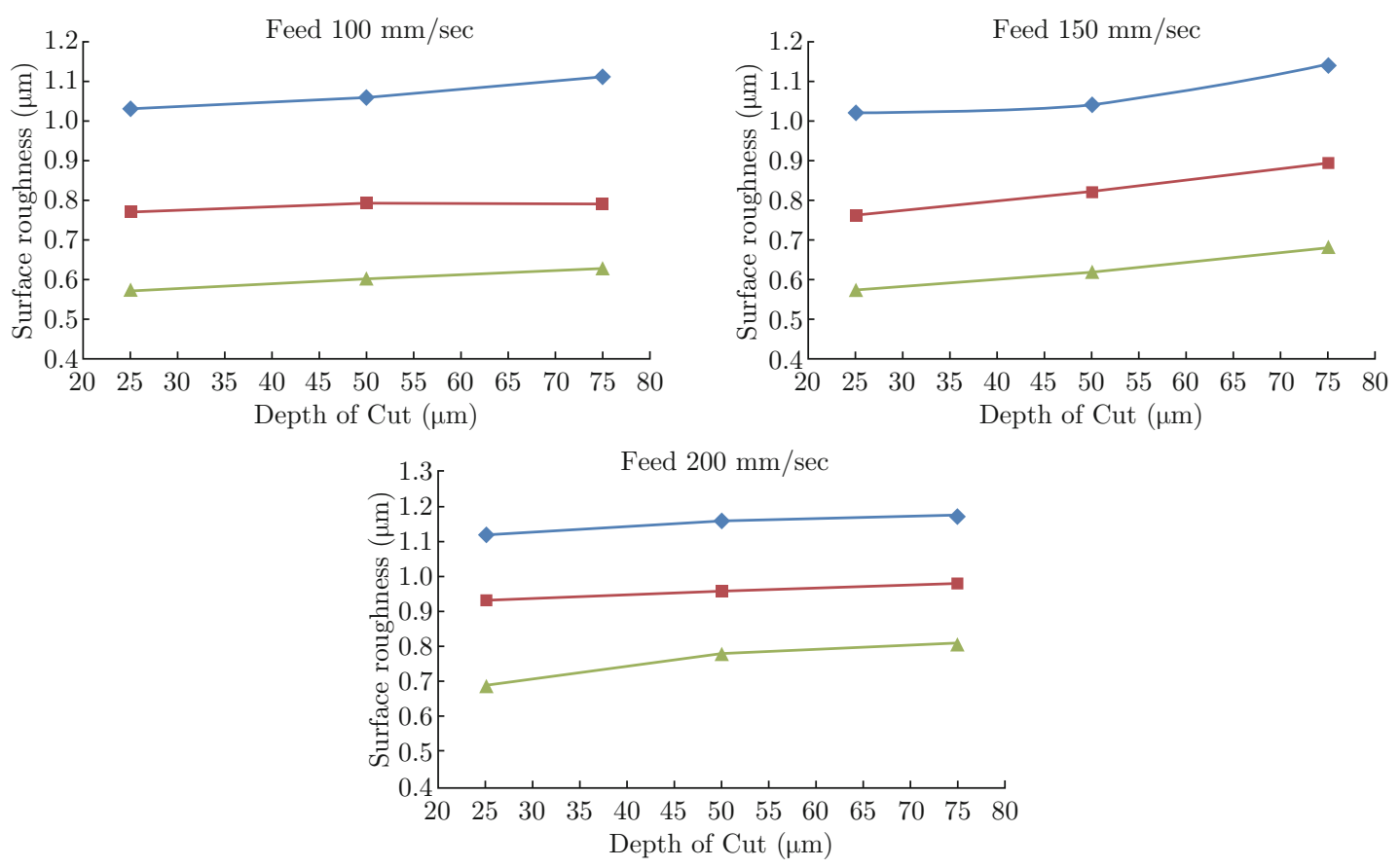

$\rightarrow$ Dry cutting $\rightarrow$-Wet cutting $₫$ Wet cutting with $1 \% \mathrm{Al}_{2} \mathrm{O}_{3}$

Fig. 4 Variation of Surface Roughness for different cutting environments.
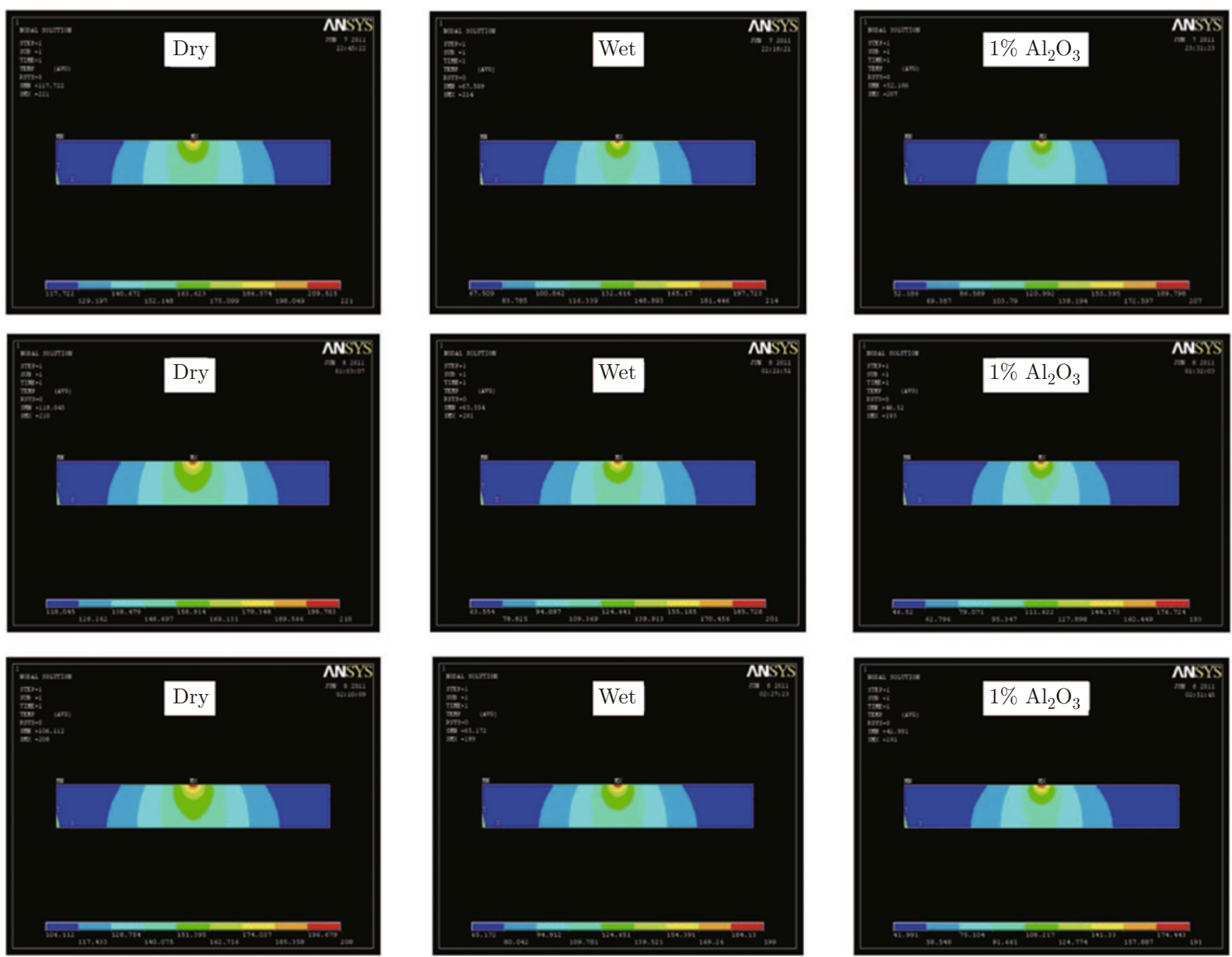

Fig. 5 Temperature distribution (a) for feed $=200 \mathrm{~mm} / \mathrm{sec}$, depth of cut=25 $\mu \mathrm{m}$ (first row) (b) for feed=150 mm/sec, depth of cut $=50 \mu \mathrm{m}$ (second row) (c) for feed $=100 \mathrm{~mm} / \mathrm{sec}$, depth of cut $=75 \mu \mathrm{m}$ (third row). 


\section{Wheel Workpiece Interface Temperature}

The major part of the work regarding temperature in metal cutting has been focused on the wheel-workpiece interface temperature (cutting temperature), this being due to the wear of grinding wheel and quality of work surface etc., as wear is sensitive to the cutting temperature in metal cutting zone. From Fig. 3 effect of dry machining, emulsifier and emulsifier $+1 \% \mathrm{Al}_{2} \mathrm{O}_{3}$ nanoparticles on wheel-workpiece interface temperature under different feed rate and OK the increase in depth of cut and feed rate, average wheel-workpiece interface temperature increases as usual due to increase in cutting energy input. However, it is also seen the interface temperatures generated decreases in emulsifier $+1 \% \mathrm{Al}_{2} \mathrm{O}_{3}$ nanofluid condition as compared to dry and plain emulsified condition. This can be due to higher thermo physical properties of emulsifier $+\mathrm{Al}_{2} \mathrm{O}_{3}$ nanofluid.

\section{Surface Roughness}

Surface roughness of the work piece was measured by Taylor-Hobson surtronic $3+$ talysurf with resolution of $0.01 \mu \mathrm{m}$, traverse length of $0.25 \mathrm{~mm}$ and traverse speed of $1 \mathrm{~mm} / \mathrm{sec}$. Figure 4 indicates that increase in surface roughness with increase in feed rate and also increasing in surface roughness with increase in depth of cut. The reduction in surface roughness was observed to be $35 \%$ to $40 \%$ in emulsifier $+1 \% \mathrm{Al}_{2} \mathrm{O}_{3}$ nanoparticles condition. This can be due to more intensive temperature generated in grinding zones, results in the development of residual stresses, micro-cracking and tempering of the work piece surface, which decrease in by adding $\mathrm{Al}_{2} \mathrm{O}_{3}$ nanoparticles results in increase of thermal conductivity and heat transfer coefficient of emulsified nanofluid compared to the plain emulsifier.

\section{Temperature Distribution}

The FEM heat transfer model has been used to estimate the energy partition OK in the real grinding application. The FEM heat transfer model traces the temporal distribution of the temperature in the workpiece, rather than only a steady-state solution. Therefore, the temperature response measured by thermocouple, which is in the time domain can be matched to FEM heat transfer model for energy partition in workpiece. Figure 5 indicates that energy partition is reduced in emulsifier $+\mathrm{Al}_{2} \mathrm{O}_{3}$ nanofluid when compared to dry and plain emulsifier.

\section{Conclusion}

Due to the enormous amount of heat energy generated at the grinding zone, in order to avoid thermal damage to workpiece, a new cutting fluid, TRIM E709 emulsifier with $\mathrm{Al}_{2} \mathrm{O}_{3}$ nanoparticles, has been developed to enhance heat transfer in grinding EN-31 steel. The major conclusions from this investigation can be summarized as follows:

- By using TRIM E709 emulsifier with $\mathrm{Al}_{2} \mathrm{O}_{3}$ nanoparticles the wheel-workpiece temperatures are reduced by 20 to $30 \%$ compared to dry and plain emulsifier.

- Surface finish also significantly improved mainly due to reduction in wear and damage at the wheel surface by the application of TRIM E709 emulsifier with $\mathrm{Al}_{2} \mathrm{O}_{3}$ nanoparticles.

- FEM grinding model has been used to simulate energy partition in dry, plain emulsifier and emulsifier with $1 \% \mathrm{Al}_{2} \mathrm{O}_{3}$ nanofluid in grinding of EN31 steel and we found decrease in energy partition and surface roughness with addition of $\mathrm{Al}_{2} \mathrm{O}_{3}$ nanoparticles.

\section{References}

[1] E. Brinksmeier, C. Heinzel and M. Wittmann, Annual CIRP, 48, 581 (1999). http://dx.doi.org/10.1016/ S0007-8506 (07)63236-3

[2] S. Malkin, R. B. Anderson, Trans. ASME, J. Eng. Ind. 96, 1184 (1974). http://dx.doi.org/10.1115/1. 3438493

[3] T. D. Howes, Annual. CIRP, 39, 313(1990). http:// dx.doi.org/10.1016/S0007-8506(07)61061-0

[4] L. R. Silva, E. C. Bianchi, R.Y. Fusse, R. E. Catai, T.V. Franca and P. R. Int. J. Machine Tools M. 47, 412 (2007). http://dx.doi.org/10.1016/j. ijmachtools. 2006.03.015

[5] S. Shaji and V. Radhakrishan, Int. J. machine tools M. 42, 733 (2002). http://dx.doi.org/10.1016/ S0890-6955 (01) 00158-4

[6] M. Alberts, K. Kalaitzidou and S. Melkote, Int. J. Machine Tools M. 49, 966 (2009). http://dx.doi.org/ 10.1016/j.ijmachtools.2009.06.005

[7] J. A. Eastman, S. R. Phillpot, S. U. S. Choi and P. Keblinski, Annu. Rev. Mater. Res. 34, 219 (2004). http://dx.doi.org/10.1146/annurev. matsci.34.052803.090621

[8] V. Vasu, K. R. Krishna and A. C. S. Kumar, Int. Energ. J. 8, 178 (2007).

[9] Z. Li, X. Feng and H. Yao, J. Mater. Sci. 39, 2267 (2004). http://dx.doi.org/10.1023/B: JMSC. 0000017804.38298 .92

[10] V. Vasu, K. R. Krishna and A. C. S. Kumar, Therm. Sci. J. 12, 27 (2008). 